\title{
Replication -On line- of an Event of Zone of Proximal Development: A Multivariate Analysis
}

\author{
Conrado Ruiz-Hernández*, Alma Delia Lupercio-Lozano, Thalía Ameyatzin Bernal-González
}

Unit of Interdisciplinary of Health and Education Sciences - FES Iztacala, National Autonomous University of Mexico (UNAM), Tlalnepantla, México

\author{
Email address: \\ cruiz.iztacala.unam@gmail.com (C. Ruiz-Hernández), educa.ambiente.cyma18@gmail.con (A. D. Lupercio-Lozano), \\ bioamethal@gmail.com (T. A. Bernal-González) \\ * Corresponding author
}

\section{To cite this article:}

Conrado Ruiz-Hernández, Alma Delia Lupercio-Lozano, Thalía Ameyatzin Bernal-González. Replication -On line- of an Event of Zone of Proximal Development: A Multivariate Analysis. Education Journal. Vol. 10, No. 2, 2021, pp. 64-67. doi: 10.11648/j.edu.20211002.15

Received: March 3, 2021; Accepted: April 14, 2021; Published: April 29, 2021

\begin{abstract}
An experimental exercise on multivariate observation of a proximal development zone process was replicated, in solving a numerical problem, with university science students. In previous studies, a face-to-face observation model was applied, in group session, but under the health contingency due to the COVID-19 pandemic, it was decided to replicate this same observation in a non-face-to-face way (online) within a virtual classroom. Forty students participated, randomly divided into two groups with twenty participants each, these being the "control" and the "experimental" group. It was possible to observe, in the case of some students of the "experimental" group, a learning process in which we infer that Vygotsky's zone of proximal development is involved. As a relevant contribution of this report, the detailed description of the algorithm used is made, for the experimental or quasi-experimental comparison of a multivariate approach, in the observation of an event where a process of proximal development zone may be involved. The equation that is described and tested is an original contribution in the fields of experimental pedagogy and educational psychology.
\end{abstract}

Keywords: Constructivism, Problem Solving, Vygotsky, Learning, Multivariate Analysis

\section{Introduction}

The genesis of learning related to problem solving, especially when the procedure is carried out in cooperation with another or other colleagues (under the assumption that at least one of the participants is more experienced in the matter), constitutes a pedagogical dynamic of strategic value [1-3].

There are several concepts frequently used in constructivism (a theory that seeks the materialistic explanation of learning, considering the individual and their social environment) that are based on problem solving. Two are mentioned here $[4,5]$ : cognitive transfer or $\mathrm{T}$ (it is the transfer of knowledge or skill that the subject has to solve a problem on his own, to another of a similar or related nature, but of more complexity) and zone of proximal development or ZPD (when the own capacity is not enough to independently solve a problem, reason why guidance or help is required, which is provided by an expert); the latter was described by the Russian psychologist Lev Vygotsky, in $1934[6,7,8]$

\section{Experimental Approach to the ZPD}

For this purpose, is necessary to design high thematic specificity problems, appropriate to support an experimental practice [9]. It must be ensured that the participants in the exercise (generally students) do not know in advance what will be explored in terms of the research objective but have a high motivation -which the teacher must promote- to achieve cooperation in the experiment [10]. It is convenient to elaborate, for each participant to answer, two problems (appropriate to the student's school level) that are related to each other, but with distinctive or cognitive particularities: the first $(\mathrm{P})$ of less relative difficulty and the second $\left(\mathrm{P}^{\prime}\right)$ of greater relative difficulty, so that it is possible to scrutinize possible cognitive transfer events among them ( $\mathrm{T}$; explained at the beginning of this article). This is necessary, in order to distinguish between the knowledge previously acquired by the respondent, from what they could learn additionally, 
through the help provided -directly or indirectly- by the expert (which is the ZPD itself).

Since 2014, our research group has carried out this type of inquiry in face-to-face group sessions. In this report, carried out in the midst of the COVID 19 pandemic (November, 2020), we repeated the same trial "at distance" in a virtual classroom, with a sample of science students, with whom we were able to work online. The different contexts of a technological and curricular nature are important for this new experience, which can explain the results -interesting by the way- that we observe on this occasion.

\section{Multivariate Analysis of the ZPD}

The following equation tries to integrate several concepts or parameters, which we consider interacting directly, without excluding other contextual aspects, in a process equal or very similar to the ZPD [11]:

$$
\mathrm{ZPD}=\mathrm{P}^{\prime}-\mathrm{T} \text {. }
$$

Where: ZPD (zone of proximal development) is determined -with a high degree of approximation- by the subtraction of $\mathrm{P}^{\prime}$ (problem of greater relative difficulty) minus $T$ (cognitive transfer), which is quantified by the coincidence between the correct answers of $\mathrm{P}$ (problem of less relative difficulty) and $\mathrm{P}^{\prime}$. In this way, the equation integrates in the same observation four quantifiable factors (in a non-parametric way, that is, by counting):

ZPD, P, $\mathrm{P}^{\prime}$ and T, as well as the participation of a "control" group and another "experimental". Which to a large extent constitutes a multivariate approach. The observation, thus carried out, disaggregates the total correct answers achieved by the respondents in $\mathrm{P}^{\prime}$ of the "experimental" group, of which the same participants had achieved in $\mathrm{P}$, where in the cases where there is a coincidence, we infer that the ability shown in $\mathrm{P}$ it probably moved to $\mathrm{P}^{\prime}$ (cognitive transfer or $\mathrm{T}$ ). In the non-coincident cases of this same "experimental" group, it is more likely that the success in $\mathrm{P}^{\prime}$ may be mainly due to a ZPD process (in which external help or intervention is involved). Similar cases for this same situation, which can occasionally occur in the "control" group, will be analyzed later in the discussion.

\section{Description of the Problems}

The problems described below are included by placing $\mathrm{P}$ first and then $\mathrm{P}$ ', interspersed in a contextual questionnaire with ten other numerical questions [12]. Regularly, university students obtain in this contextual numerical questionnaire, grade averages between 9.2 and 9.5.

P: sum of a polynomial of two terms (the concept is explained in problem $\mathrm{P}^{\prime}$ ).

Execute the following operation:

$$
2+3 \times 4 .
$$

The correct result is 14 . This sum, based on the historical references that we have, represents high to medium difficulty in university students, although in recent years, we have observed a notable improvement in this performance, which may be due to a greater attention to the teaching of elementary mathematics or to particular curricular events. In the cases of making a mistake, this is due to the inadvertent or non-correct identification of the terms present in a polynomial, which constitutes the remnant of poorly attended learning in basic education $[13,14]$.

P': This problem is presented to the participants preceded by the following informative heading: "In serial operations or polynomials, the independent computations and values called 'terms' are separated by addition or subtraction. This is related to the 'hierarchy in the order of operations principle'. Take a good look and carefully execute the following operation".

$$
3.2+4.4 \times 2+8 \text {. }
$$

The correct result is 20 . In this last problem, the presence of a third term and where decimal numbers also participate, usually represents a greater difficulty for students than with P. In special designs (particularly in the "experimental" group), with the intention of increasing the help to the respondent, parentheses can be added in the second term of $\mathrm{P}^{\prime}$ [3.2 $\left.+(4.4 \times 2)+8\right]$, however, despite being a very effective help, it is a mathematical incorrectness.

\section{Experimental Design}

\subsection{Objectives}

1. Verify the consistency of a multivariate observation model on a zone of proximal development event in problem solving.

2. Recognize the usefulness of an informative notice, in the experimental or quasi-experimental observation, of learning processes related to Vygotsky's zone of proximal development.

\subsection{Hypothesis}

"Most of the participants will be able to solve a simple problem, but in some particular cases, an informative notice can be of great help to achieve the success".

\subsection{Subjects and Procedure}

Forty students who are beginning their training in a scientific career participated, with these two groups of twenty members each were randomly organized, who were part of two virtual classrooms, thus leaving the "control" and the "experimental" group. The difference between the two groups is that $\mathrm{P}^{\prime}$ is presented in the "control" group without an informative heading (what constitutes the intervention or help) and, in the "experimental" group the informative heading is presented in $\mathrm{P}^{\prime}$, indicated in the description of this problem. Work was carried out over the Internet "remotely", with the platform of Google questionnaires, for open numerical responses and ensuring the isolation of the 
participants during the exercise. As additional information, the participants were asked to send by email, the image of the procedures -written with pencil and paper, without using a calculator- that they developed in the solution of the twelve questions of the questionnaire.

\section{Results}

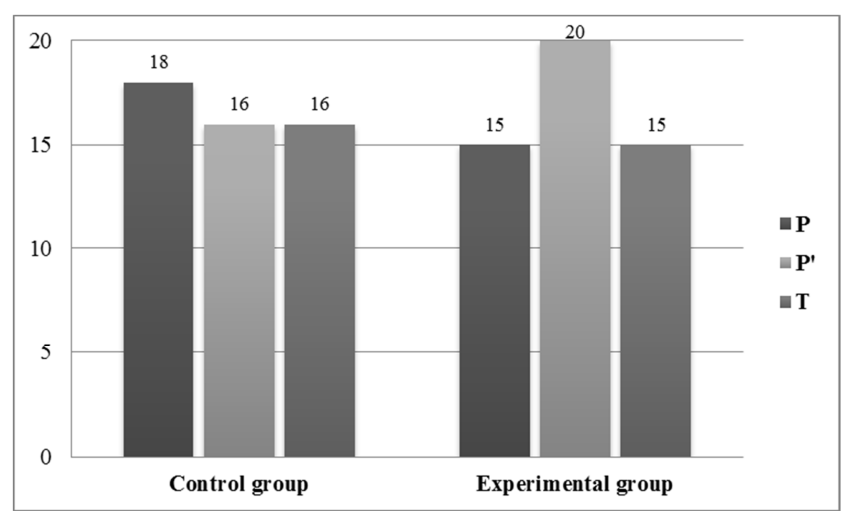

Figure 1. Show the successes obtained in the two problems and the coincidence between both, for the two treatments.

What is observed is consistent with the results of other previous reports, only that this time the differences were in the range of high grades (from 75 to $100 \%$ correct answers), which shows a notable improvement in these students, with respect to performance, which with these same problems, achieved similar students ten years ago [15]; where the range of qualifications was from 30 to $50 \%$ correct answers. The mistakes in the sums, both in $\mathrm{P}$ and $\mathrm{P}^{\prime}$ of both groups ("control" and "experimental"), are due to the same cause: the inadvertence of the terms of the sums, that is, by carrying out the mechanizations in a row without taking into account the separation of the terms by addition or subtraction. Taking P (2 $+3 \times 4=14)$ as an example, this error consists of first adding 2 +3 and then multiplying at the end -incorrectly the previous sum- by 4 , which results in a failed result of 20 . This same error is usually replicated with $\mathrm{P}^{\prime}(3.2+4.4 \times 2+8=20)$, where a third term is also presented and there are decimal numbers. In a case of the "control" group, the participant erred in $\mathrm{P}^{\prime}$ due to a probable calculation error in the sum of the decimals, since 20 being the correct result, he wrote 19.8; this participant, despite having correctly recognized the terms, was finally wrong in the result of the sum.

Applying the equation: $\mathrm{ZPD}=\mathrm{P}^{\prime}-\mathrm{T}$, both for the "control" and the "experimental" group, we have that for the first ZPD $=0$ and, for the second, $Z P D=5$.

The difference of these values, with the Student's $t$ test, for $(20+20-2=38$ degrees of freedom), in a two-tailed test, reaches a statistical certainty of $97.5 \%$ confidence. Which is extremely remarkable, considering that we worked with two small samples $(\mathrm{N}=20)$.

\section{Discussion}

This experimental exercise carried out with two groups of twenty students with differentiated treatments and applied "at a distance", over the Internet and in virtual classrooms, yielded consistent data with respect to the multivariate approach in the study of Vygotsky's zone of proximal development or, less, of a cognitive process very similar to this one. Although previously there were reports with similar experiences, where the ranges of successes showed performances from low to intermediate with these same applied problems, it is observed that on this occasion the degrees of difficulty, both for $\mathrm{P}$ and $\mathrm{P}$, allowed the participants obtain a greater number of correct answers, which did not affect the functionality of the applied observation model. In other words, this observation model is adaptable to different cognitive situations, being able to operate both in low, medium and highest difficulty grades.

For the case that in $\mathrm{P}^{\prime}$ of the "control" group, a participant can be correct having previously erred in $\mathrm{P}$ (without the coincidence between the correct answers of both problems), with the example of the sums of applied polynomials, not we have references. However, in the case of another issue related to environmental education and the culture of recycling [16], if there is a reported antecedent (not dealing with numerical problems), where a few participants that initially they erred in $\mathrm{P}$ and later they got it right in $\mathrm{P}$ ', without receiving intervention or external help, this can be explained by a different process, although linked to the ZPD, which is the zone of real development or ZRD; which is when the subject realizes on their own or due to previous experiences of a misunderstood or understood learning and he himself (without external help) can improve or correct it.

This analysis must be articulated with recent research regarding the evolution of Vygotsky's concepts, as well as other cognitive processes directly or indirectly related to the ZPD $[17,18]$.

\section{Conclusions}

The multivariate observational model of the ZPD (carried out through a brief educational intervention and without a medium or long-term evaluation), as demonstrated in this trial, is clearly effective and consistent. It can operate with different qualification ranges, regardless of the degree of difficulty of the problems or educational topics that the observer wants to involve (here mention is made of numerical and environmental education topics). Likewise, the model is adaptable to working with different sample sizes, although it is preferable for these to be medium to large (40100 participants or more). Appropriate statistical procedures for its analysis can be the Student's t test and the variance and covariance estimates for non-parametric versions. The analysis of covariance is especially useful to estimate the probabilistic influence of $\mathrm{P}$ (associated variable) on $\mathrm{P}^{\prime}$ (dependent variable), mediating between them, the intervention or help provided to the subjects of the "experimental" group (independent variable). Remember that this intervention is included in the informative heading present in $\mathrm{P}^{\prime}$. In situations with an abundant incidence of 
coincidences between the correct answers of $\mathrm{P}$ and $\mathrm{P}^{\prime}$, both in the control and experimental groups, the probabilistic influence of $\mathrm{P}$ on $\mathrm{P}^{\prime}$ is usually high. The Student's t-test allows us to analyze separately, disaggregating from the final result $\left(Z P D=\mathrm{P}^{\prime}-\mathrm{T}\right)$, what may more properly be due to the ZPD than to the cognitive transfer $(\mathrm{T})$ or to another possible cause.

\section{Acknowledgements}

This research was funded by the UNAM Support Program for Research and Technological Innovation Projects: PAPIIT IN310719. Particularly, in the development of methods, for conducting complex studies. We are grateful to the participating students of the UNAM-Iztacala biology degree, who with their solidarity and committed collaboration, made this report possible.

\section{References}

[1] Flavell, J. (1976). Metacognitive aspects of problem solving. In L. B. Resnick, The nature of intelligence (pp. 231-235). Hillsdale, Nueva Jersey: Lawrence Erlbarum Associates.

[2] Bunce, G. (2003). Educational implications of Vygotsky's zone of proximal development on collaborative work in the classroom, in Developing Expertise in Teaching. Available at: http://blogs.ubc.ca/vygotsky/files/2013/11/vygotsky-and-theclassroom.pdf

[3] Shamir, A., Mevarech, Z. \& Gida, C. (2009). The assessment of meta-cognition in different contexts: individualized Vs. peer assisted learning. Metacognition and Learning, 4 (1), 47 61 .

[4] Flavell, J. H. (2004). Theory of mind development: retrospect and prospect. Journal of Developmental Psychology, 50 (3), 274-290.

[5] Raynald, F. \& Rieunier, A. (2010). Pedagogía. Diccionario de conceptos claves. Madrid: Ediciones Popular.

[6] Vigotsky, L. (1988 ed.). El desarrollo de los procesos psicológicos superiores. México: Editorial Crítica, Grupo Editorial Grijalbo.

[7] Chaiklin, S. (2003). The zone of proximal development in Vygotsky's analysis of learning and instruction, en A. Kozulin (ed.), Vygotsky's educational theory and practice in cultural context. Cambridge: Cambridge University Press. Available at: https://doi.org/10.1017/CBO9780511840975.004
[8] Veresov, N. (2004). Zone of proximal development (ZPD): the hidden dimension? In: A. Ostern y R. Heila-Ylikallio, Language as culture-tensions in time and space (vol. 1). Vasa: Helsinki, Available at: http://nveresov.narod.ru/ZPD.pdf

[9] Ruiz, C. (2014). Experimento educativo en ZDP, Ciencia y Desarrollo, 40 (272), 22-23.

[10] Ruiz, C. (2015). Hacia una comprobación experimental en la zona de desarrollo próximo de Vigotsky, Ciencia ergo-sum, [SI], 22 (2): 167-171.

[11] Ruiz-Hernández, C.; Lupercio Lozano, A. D. \& Bernal González, T. A. (2017). Towards an Experimental Verification of Vygotsky's Zone of Proximal Development: A Docimological Approach, Education Journal. 6 (1): 47-50. doi: 10.11648/j.edu.20170601.16

[12] Ruiz-Hernández, C.; Lupercio Lozano, A. D. \& Bernal González T. A. (2015). The Scope and Limitations of Brief Interventions for Remedial Education: An Experimental Approach in a Numeracy Case. International Journal of Secondary Education, 3 (4): 32-36.

[13] Alatorre, S. (2002). Aspectos temáticos del efecto remanente de las matemáticas en México. In: Algunos problemas de la educación en matemáticas en México, A. de la Peña (compiler), México. D. F., Siglo XXI Editores, 51-112.

[14] Ruiz, C. (2012). Pocos más muchos. Contexto sociocultural, al hacer cuentas, Ciencia y Desarrollo, enero-ferero (38) 82579, 30-31.

[15] Ruiz-Hernández, C.; Lupercio-Lozano, A. D.; BernalGonzález, T. A.; Torner-Morales, F. J. \& Muñoz-López, J. L. (2020a). Numeracy and Environmental Skills with Indicators: Educational Micro-Assessment in University Students. Global Research in Higher Education, 3 (3): 42-50.

[16] Ruiz-Hernández, C.; Lupercio-Lozano, A. D. \& BernalGonzález, T. A. (2020b). A Zone of Proximal Development Process in the Selective Disposal of Urban Solid Waste: Problem Solving with Two Assembled Materials, Education Journal. 9 (2): 48-51. doi: 10.11648/j.edu.20200902.13

[17] Keith S. Taber \& Xinyue Li. (2020). Chapter 1. The Vicarious and the Virtual: A Vygotskian Perspective on Digital Learning Resources as Tools for Scaffolding Conceptual Development. Advances in Psychology Research. 143: 22-65.

[18] Callan, G. L., \& Cleary, T. J. (2019). Examining cyclical phase relations and predictive influences of self-regulated learning processes on mathematics task performance. Metacognition and Learning, 14 (1), 43-63. Available at: https://doi.org/10.1007/s11409-019-09191-x. 